\title{
THE
}

1989

\section{Secondary circulations in the bottom boundary layer over sedimentary furrows}

\author{
Bruce E. Viekman \\ University of Rhode Island \\ Mark Wimbush \\ University of Rhode Island, mwimbush@uri.edu \\ John C. Van Leer
}

Follow this and additional works at: https://digitalcommons.uri.edu/gsofacpubs

Terms of Use

All rights reserved under copyright.

\section{Citation/Publisher Attribution}

Viekman, B. E., Wimbush, M., \& Van Leer, J. C. (1989). Secondary circulations in the bottom boundary layer over sedimentary furrows. Journal of Geophysical Research: Oceans, 94(C7), 9721-9730. doi: 10.1029/JC094iC07p09721

Available at: https://doi.org/10.1029/JC094iC07p09721

This Article is brought to you for free and open access by the Graduate School of Oceanography at DigitalCommons@URI. It has been accepted for inclusion in Graduate School of Oceanography Faculty Publications by an authorized administrator of DigitalCommons@URI. For more information, please contact digitalcommons-group@uri.edu. 


\title{
Secondary Circulations in the Bottom Boundary Layer Over Sedimentary Furrows
}

\author{
Bruce E. Viekman ${ }^{2}$ and Mark Wimbush \\ Graduate School of Oceanography, University of Rhode Island, Narragansett \\ JOHN C. VAN LEER \\ Rosenstiel School of Marine and Atmospheric Science, University of Miami, Miami, Florida
}

\begin{abstract}
Secondary circulation is known to be an important feature of many atmospheric and laboratory boundary layers. The presence of streamwise, helical, counterrotating vortices is documented here for the first time in the bottom boundary layer of a large natural body of water. Simultaneous vertical profiles of velocity and temperature were recorded on either side of a sedimentary furrow on the floor of Lake Superior (depth $=100 \mathrm{~m}$ ) in November 1985. Flow roughness length $z_{\mathrm{o}}$ was estimated to be $0.3 \mathrm{~cm}$. Friction velocity $u_{*}$ and turbulent boundary layer thickness $L_{W}$ were estimated for each profile allowing for stratification effects. Typically, $L_{W} \approx 10 \mathrm{~m}$. Thermal stratification near the lake bed was an important constraint to boundary layer development; bottom mixed layers were absent in most cases. Mean flow toward the furrow at lower levels within the boundary layer $\left(z / L_{W}<0.37\right)$ and mean flow away from the furrow at higher levels $\left(0.37<z / L_{W}<1.65\right)$ were observed for near-bottom speeds greater than $6 \mathrm{~cm} / \mathrm{s}$ when mean How direction was within $25^{\circ}$ of the furrow direction. This implies helical vortex pair circulations with upward motion over the furrow, consistent with earlier hypotheses. Cross-stream (secondary) flows were typically $5 \%$ of the free stream (primary flow) speed. Streamwise vorticity in the range $1.5 \mathrm{~m} \leq z \leq 5 \mathrm{~m}$ was estimated to be $2.1 \times 10^{-3} \mathrm{~s}^{-1}$.
\end{abstract}

\section{INTRODUCTION}

Streamwise, counterrotating helical vortices are a frequently occurring organized structure in turbulent flows and have been observed in both laboratory and geophysical boundary layers. In the laboratory, the most familiar helical circulations are Taylor vortices, the fundamental form of instability in rotating Couette flow, that is, flow between concentric cylinders rotated at different rates. A special case of Taylor vortices, called Görtler vortices, occurs in the boundary layer of flow along a concavely curved wall. Townsend [1970] found that the dominant eddies in inhomogeneous shear flow could be described as a vortex pair, inclined at an angle to the mean flow direction.

In an analysis of secondary circulations in wind tunnel boundary layers, Townsend [1976] found that periodic crossflow variations in surface stress could also be responsible for secondary circulations: vortices were sustained when the ratio of roughness variation wavelength to mean boundary layer thickness was less than approximately 4.2. Longer wavelengths induced negative secondary circulation growth rates. Those results were confirmed both experimentally and theoretically by McLean [1981], who used transversely alternating bed roughness in a flume to induce secondary flows. He observed peak secondary circulation amplitudes when the ratio of rough strip separation to water depth was 4. In an investigation of the boundary layer over a plate with

1 Now at Marine Science Section, U.S. Coast Guard Academy, New London, Connecticut.

Copyright 1989 by the American Geophysical Union.

Paper number 89JC00416.

$0148-0227 / 89 / 89 \mathrm{JC}-00416 \$ 05.00$ a free edge along the mean flow direction, Elder [1960] found that vortices were formed near the free edge as a product of differential stress, with the main vorticity concentrated above the free edge. The associated circulation extended to about two boundary layer thicknesses above the plate. Cantwell [1981] describes many instances where vortex circulation is found in boundary layers. Paired linear vortices are seen commonly in areas of convection, but other forms, such as horseshoe vortices, are also seen in a variety of turbulent conditions.

Geophysical examples of counterrotating helical vortex circulations include the common Langmuir circulation in the wind-driven boundary layer below the sea surface. The generation mechanism for Langmuir cells is apparently different from that of the other vortices we have described: it is thought to be wave-induced Stokes drift combined with current shear [Leibovich, 1983]. This mechanism is not available in turbulent boundary layers over a fixed surface; nevertheless longitudinal vortex rolls form in the boundary layer at the base of the atmosphere. "Clond streets" are commonly seen in satellite photographs, indicating uplift-induced convection and condensation. The most complete work on these atmospheric secondary circulations [Brown, 1970] models the rolls as an equilibrium perturbation of the primary flow, the amplitude determined by the energy balance. Brown [1970] relates the appearance of secondary circulations, in part, to changes in bed roughness. For example, the change in surface roughness caused by wind passing from sea to shore can cause secondary circulations to form.

The bottom boundary layer (BBL) has similar dynamics to the atmospheric surface layer, though buoyancy forces are generally much less important in the BBL case. But despite the thorough documentation of atmospheric secondary circulations, very little is known about secondary flows in the BBL of seas or lakes. Sedimentologists [e.g., Flood, 1978, 
1983] have suggested that these secondary circulations exist and are related to the appearance or maintenance of bed forms such as furrows and sand ribbons seen on the bed in regions of moderately fast and directionally steady currents. In this paper we examine the BBL in a region of sedimentary furrows. From the records of a pair of profiling current meters, we document the structure of the BBL and analyze simultaneous profiles to study secondary circulations. The relationship between these circulations and thermal stratification, bottom stress, flow speed, and Richardson number is examined, and streamwise vorticity of the circulations is determined.

\section{METhOD}

Two Mark III Cyclesondes were deployed in the midst of a known sedimentary furrow field at $100 \mathrm{~m}$ depth in Lake Superior in fall 1985 . The Cyclesonde is a vertically profiling current meter, which rises and falls at set times on a taut wire mooring. It records the numbers of rotations of two horizontally mounted Aanderaa rotors during a set time interval, together with spot samples of temperature, pressure, instrument heading, instrument pitch, and several internal variables at the end of the interval. The instrument pivots freely about the mooring and is oriented by the current so that the rotor axes are perpendicular to the flow direction. The heading of the instrument then gives the current direction. Nonferrous materials (e.g., lead anchors) were used in the moorings to avoid disturbing the Earth's magnetic field observed by the heading compasses. For a complete description of the Mark I Cyclesonde, an earlier variant, see Van Leer et al. [1974]. Profiling limits were determined by stops clamped onto the taut wire about $1.4 \mathrm{~m}$ above the bottom and $14 \mathrm{~m}$ below the surface. A float $10 \mathrm{~m}$ below the surface terminated the upper end of each mooring. Table 1 gives a summary of the moorings. Note that the northern Cyclesonde (designated $N$ ) profiled for 6 days, while the southern Cyclesonde (designated S) continued profiling for a further 24.

In this deployment, a complete profiling cycle consisted of two profiles and lasted 6 hours. Take, for example, a cycle beginning at 0200 eastern standard time (EST). At 0201 the Cyclesonde bladder inflates, and the instrument begins an upward profile lasting about $20 \mathrm{~min}$. The sampling interval is $60 \mathrm{~s}$, until 0232 when it increases to $252 \mathrm{~s}$. The Cyclesonde remains at the top stop of the mooring until 0501. At that time the bladder deflates, and the instrument begins a downward profile lasting about $20 \mathrm{~min}$. From 0501 to 0532 the sampling interval is again $60 \mathrm{~s}$, and thereafter, 252 s. Until the end of the cycle at 0800 EST the Cyclesonde remains at the bottom stop. The two Cyclesonde quartz crystal clocks were synchronized at the start so that their profiling cycles would be synchronized.

The Lake Superior furrow field is well documented [Flood and Johnson, 1984; Flood, 1983, 1989]. Furrow separation varies from $20 \mathrm{~m}$ to $60 \mathrm{~m}$, with typical widths of $5 \mathrm{~m}$ and depths of $1 \mathrm{~m}$. Furrows in the area are oriented about $080^{\circ}-$ $260^{\circ}$ (magnetic variation for the area is zero). Furrow separation in the immediate area of the instruments is approximately $60 \mathrm{~m}$. The Cyclesondes were placed in the furrow field near $47^{\circ} 29.4^{\prime} \mathrm{N}, 87^{\circ} 51.4^{\prime} \mathrm{W}$, about $2 \mathrm{~km}$ north of Copper Harbor Lighthouse on the north shore of Michigan's Keweenaw Peninsula. Figure 1 shows the bottom topography in the area.
TABLE 1. Mooring Summary

\begin{tabular}{|c|c|c|}
\hline & $\begin{array}{c}\text { Mooring N } \\
\text { Cyclesonde } 66\end{array}$ & $\begin{array}{c}\text { Mooring S } \\
\text { Cyclesonde } 64\end{array}$ \\
\hline $\begin{array}{l}\text { Start date } \\
\text { Start time (EST) }\end{array}$ & $\begin{array}{c}\text { Oct. } 28,1985 \\
1800\end{array}$ & $\begin{array}{c}\text { Oct. } 28,1985 \\
1300\end{array}$ \\
\hline $\begin{array}{l}\text { Stop date } \\
\text { Stop time (EST) }\end{array}$ & $\begin{array}{c}\text { Nov. } 5,1985 \\
2100\end{array}$ & $\begin{array}{c}\text { Nov. } 29,1985 \\
0100\end{array}$ \\
\hline Last usable profile & $\begin{array}{c}\text { Nov. 3, } 1985 \\
2300\end{array}$ & $\begin{array}{c}\text { Nov. } 27,1985 \\
0000\end{array}$ \\
\hline Termination cause & $\begin{array}{c}\text { ruptured } \\
\text { buoyancy } \\
\text { bladder }\end{array}$ & $\begin{array}{c}\text { gas } \\
\text { expended }\end{array}$ \\
\hline $\begin{array}{l}\text { Typical vertical } \\
\text { profiling speed }\end{array}$ & $14 \mathrm{~cm} / \mathrm{sec}$ & $10 \mathrm{~cm} / \mathrm{sec}$ \\
\hline $\begin{array}{l}\text { Position relative } \\
\text { to furrow }\end{array}$ & $19 \mathrm{~m}$ north & $13 \mathrm{~m}$ south \\
\hline $\begin{array}{l}\text { Bottom stop height } \\
\text { above lake bed }\end{array}$ & $1.59 \mathrm{~m}$ & $1.25 \mathrm{~m}$ \\
\hline
\end{tabular}

The profiling interval was one profile every 3 hours, beginning at $0200,0500,0800$, etc., EST. The sample interval was $60 \mathrm{~s}$ for the first $30 \mathrm{~min}$ of the profiling hours; otherwise, it was $252 \mathrm{~s}$.

Mooring locations relative to the nearest furrow were determined from echo sounder and side scan sonar surveys. In the deployment, the moorings were positioned $39 \mathrm{~m}$ apart, with a single furrow between them (Figure 2). On returning to the area to recover the moorings the following June, an echo sounder survey revealed no furrow between the moorings. Nevertheless, mooring-to-mooring orientation and separation appeared unchanged, indicating that the mooring anchors had not moved over the winter. The Cyclesondes were redeployed at that time, but the June data showed nearly quiescent conditions throughout the record: hourly averaged speeds $1.4 \mathrm{~m}$ from the bottom were below the rotor stall speed for 40 out of 57 total hours, and average speeds were over $6 \mathrm{~cm} / \mathrm{s}$ for only 4 hours.

The October-November data-gathering period was intended to coincide approximately with the period of fall "overturn" in the lake, when stratification is minimized by surface cooling to temperatures near that of the maximum density of fresh water. But during the 6 days in which both Cyclesondes were profiling, there was still significant residual summer stratification: median Brunt- $V$ äisälä frequency at $15 \mathrm{~m}$ above the lake bed was $5 \times 10^{-3} \mathrm{~s}^{-1}$ during this period.

Laboratory calibrations of the temperature, pressure, and heading cells were conducted in Miami before the experiment. The pressure cells were recalibrated after the deployment. The heading cell slope factors were checked in Copper Harbor after the experiment to allow for any possible effects due to dip angle difference between Miami and Copper Harbor. Rotor count calibrations were based on tow tank results carried out in 1988. The stall speed of the Cyclesonde's Aanderaa rotors is $2.48 \mathrm{~cm} / \mathrm{s}$, so flows below that threshold speed were not resolved. In this work, time intervals in which the rotors were stalled were assigned a flow speed of $1.24 \mathrm{~cm} / \mathrm{s}$ (this only occurred when the Cyclesonde was resting at the bottom or top stop). 


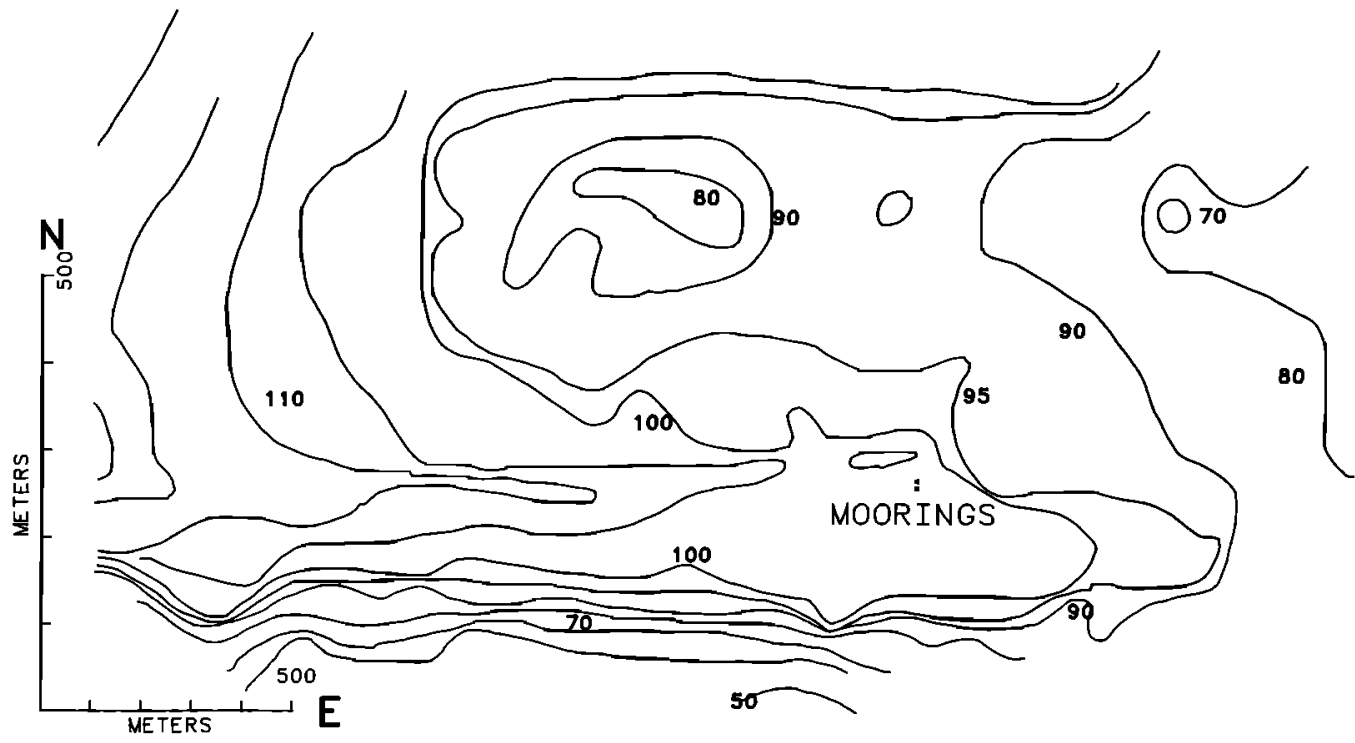

Fig. 1. Bottom at the study location. The contour interval is $10 \mathrm{~m}$ for depths up to $90 \mathrm{~m}$ and $5 \mathrm{~m}$ thereafter. Note the dissimilarity in the north and east length scales.

To determine the height above bottom corresponding to a given speed sample, a three-step procedure was used. First, recorded pressures were corrected for instrument pitch, as the pressure cell and rotors were on opposite ends of the 2.5$m$ instrument body. Second, the pressure corresponding to a speed observation was taken as the average of the spot sam- ples of pitch-corrected pressure at the beginning and end of the sampling interval, since recorded rotor counts measured the speed averaged over the time interval. The pressures corresponding to speed observations were therefore different from those corresponding to heading and temperature observations, which were spot samples taken simultaneously

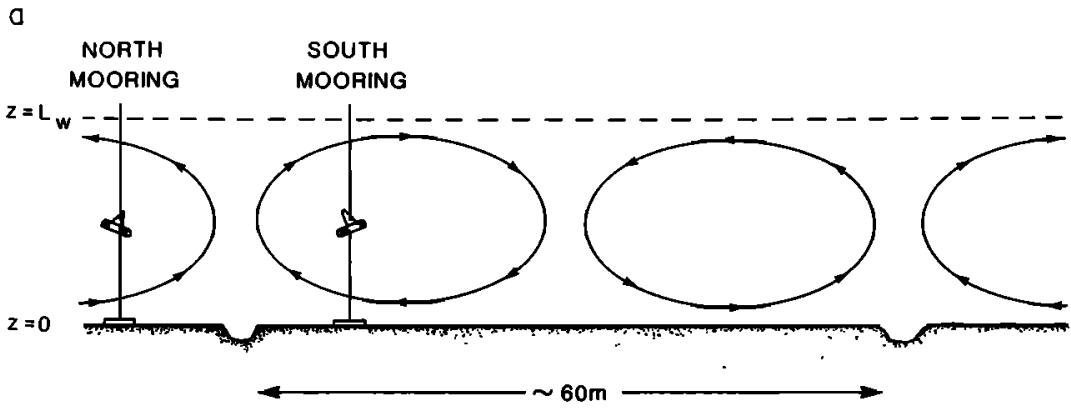

b.

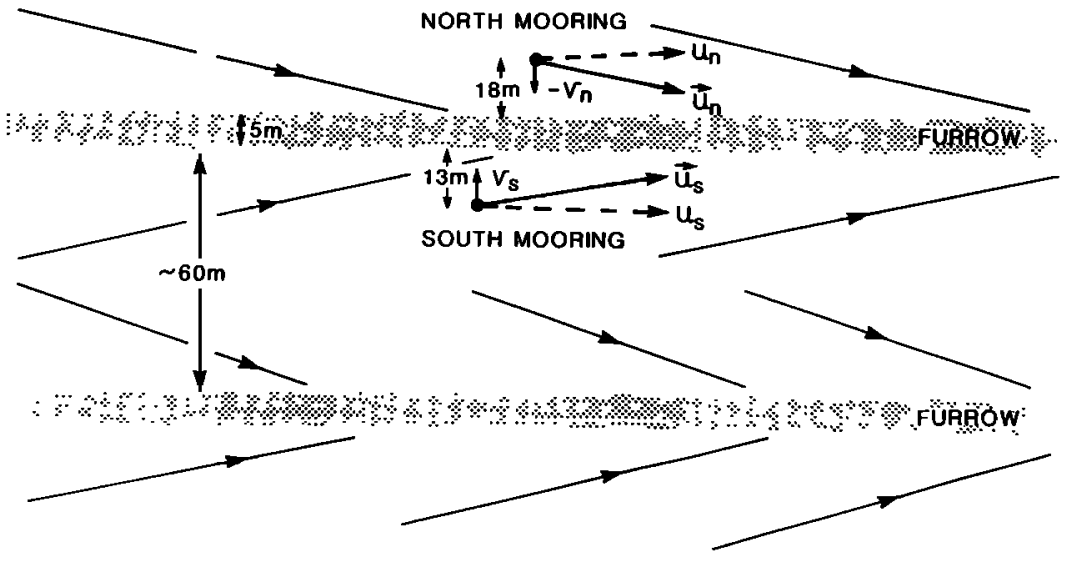

Fig. 2. Diagrams (not to scale) of Cyclesonde mooring positions in relation to furrows and hypothesized mean flow field, looking ( $a$ ) downstream and (b) downward from above. Unlabeled arrows show the mean flow direction; in Figure $2 b$ these arrows refer to flow near the bed. 

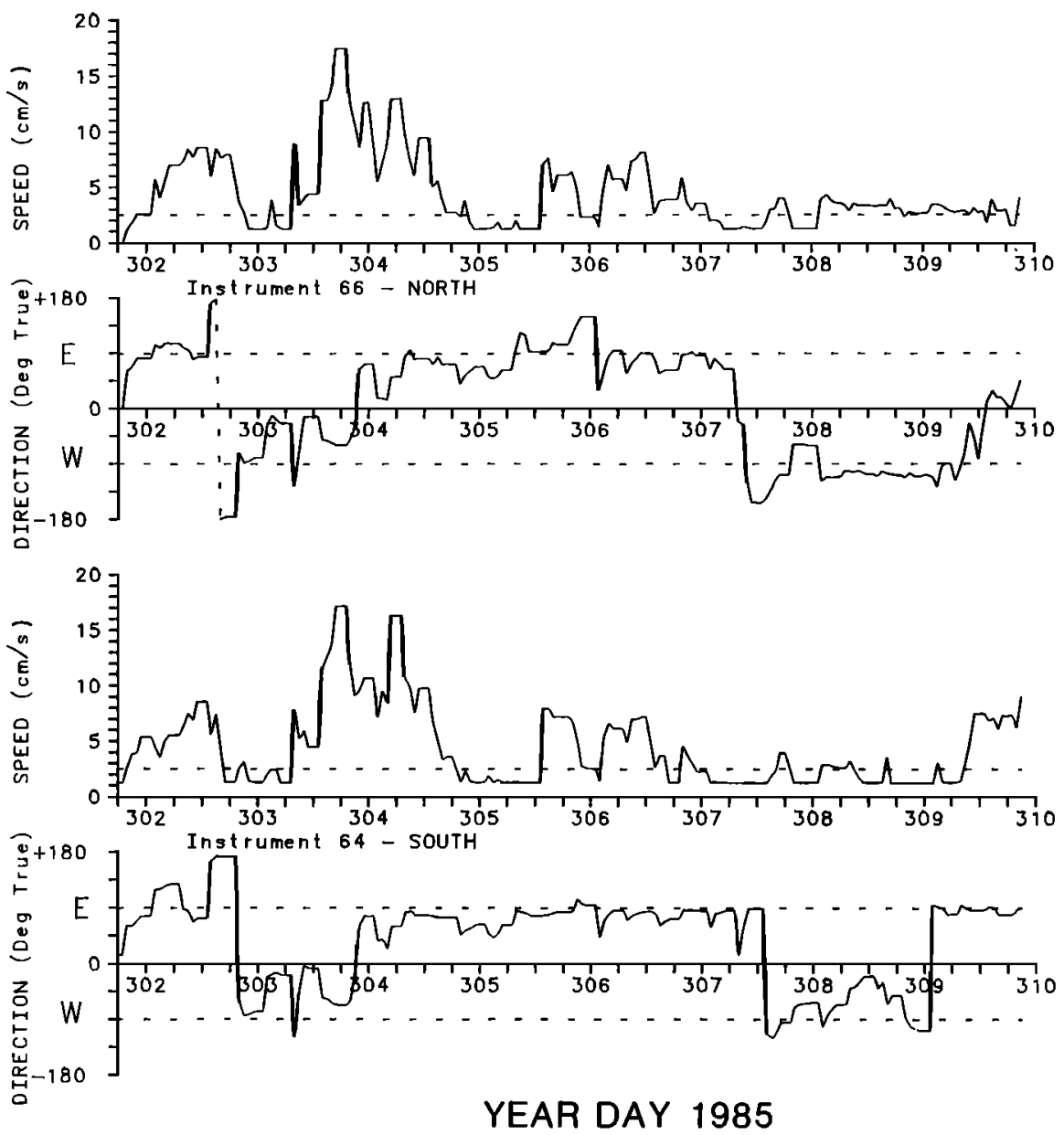

Fig. 3. Hourly averaged near-bottorn current speed and direction observed by the two cyclesondes. The top two panels show north mooring (N) data, and the bottom two panels show south mooring (S) data, during the period when both instruments were working. Numbered year day ticks correspond to zero hours eastern standard time. Rotor stall speed $(2.48 \mathrm{~cm} / \mathrm{s})$ is shown by a dashed line.

with the pressure. Finally, each pressure was converted to instrument depth, and this in turn was converted to height above the bottom by calculating the average depth of the bottom stop for the nearest hour when the instrument was on the bottom stop, adding the known distance from the stop to the lake bed and subtracting the depth of the instrument. This procedure compensated for any variations in atmospheric pressure, lake level, and drift of the pressure sensor occurring during the study. The distance from the bottom stop to the lake bed was determined from a postrecovery examination of the bottom sediment line on the mooring anchor.

\section{REsults}

\subsection{Near-Bottom Flow}

Figure 3 shows time series plots of hourly averaged speed and direction (direction averages formed by averaging components of unit vectors with the measured directions) of the near-bottom currents measured by the two Cyclesondes. We use "near-bottom" throughout to refer to data recorded while the instruments rested on the bottom stop $(z \approx 1.4 \mathrm{~m})$. Date is given by year day, the useful start of profiling in records $\mathrm{N}$ and $\mathrm{S}$ being year day 302 (October 29, 1985). The last useful profile of record $N$ occurred at the end of year day 307. Thereafter this Cyclesonde remained on the bottom stop, and two days later ceased recording. Record S continued for another 24 days (Table 1), but Figure 3 shows only the period when both instruments were working. Hour refers to eastern standard time on the 24-hour clock. During the 6-hour period of a given profiling cycle, the instrument rested on the bottom stop for about $2 \frac{1}{2}$ hours. There is no information on near-bottom flow conditions in the other approximately $3 \frac{1}{2}$ hours.

The record of near-bottom flow consists of three vigorous periods, separated by low-speed intervals. These high-speed events, during which flow speed averages from both instruments exceed $6 \mathrm{~cm} / \mathrm{s}$, extend over a total of 70 hours, or $46 \%$ of the total record. Flow direction is generally along the coastline (i.e., roughly parallel to the furrows). Most of the time the flow is eastward, with one brief reversal to intense northwestward flow, with a peak of $13.8 \mathrm{~cm} / \mathrm{s}$ at day 303, hour 16. The highest flow speed seen in the total record was at year day 325 , hour 4 , after the end of record $N$ : the near-bottom average flow was $29.6 \mathrm{~cm} / \mathrm{s}$ eastward $\left(084^{\circ}\right)$, and this peak occurred within a 51-hour high-speed event during a violent storm over the lake.

Cross-correlation functions of the near-bottom hourly data for record $\mathrm{N}$ with record $\mathrm{S}$ were computed for $u$ (eastward) and for $v$ (northward) to confirm the correct relative 


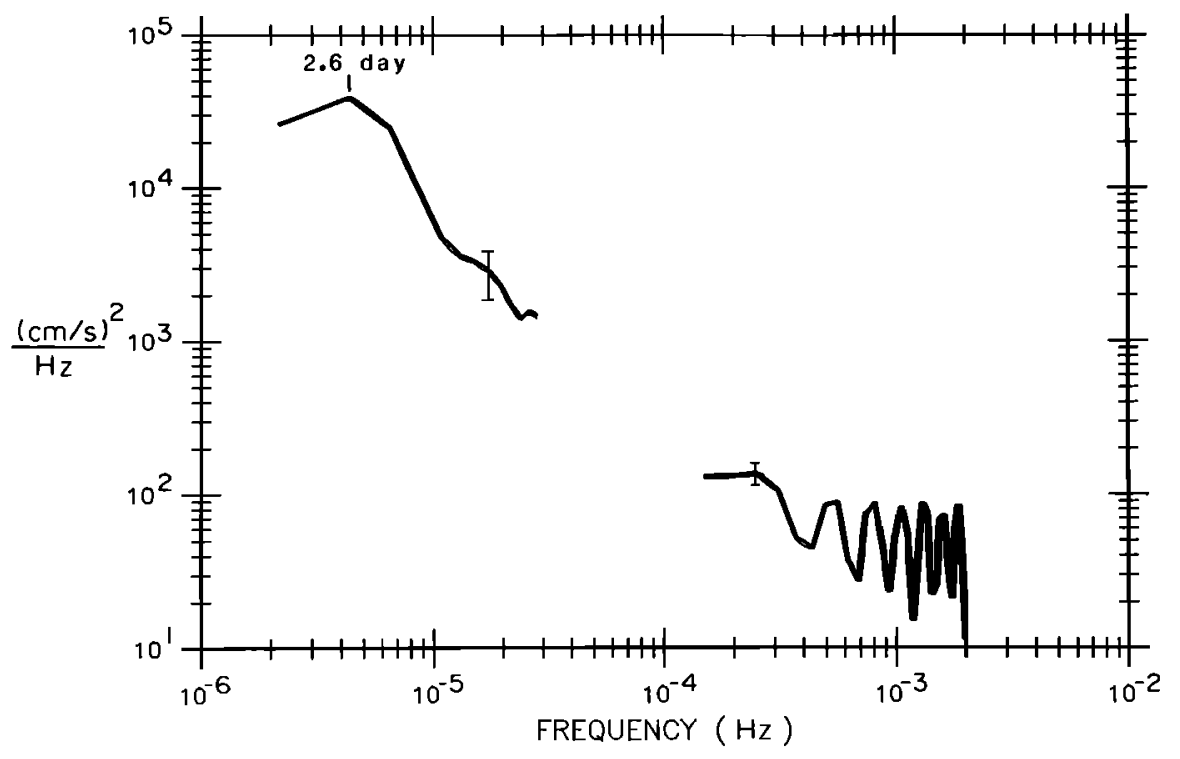

Fig. 4. Autospectra of near-bottom speed, computed from two different treat ments of 32-day record S (see text); $95 \%$ confidence intervals are shown by error bars.

timing of the records. The $u$ component correlation peaked with S lagging $\mathrm{N}$ by 1 hour; the value at zero lag was $95 \%$ of the 1-hour lag maximum. The more energetic $v$ component correlation peaked strongly at zero lag. The $e$-folding time on both curves was about 7 hours.

Spectral estimates for near-bottom scalar speed were determined from record $\mathrm{S}$ using the full 32 days duration (Figure 4). Because of the gaps in the record caused by the transit of the instrument, two separate spectra were calculated using different treatments of the data. The 102 periods where the instrument rested on the bottom stop provided 102 high-frequency $\left(6 \times 10^{-5}\right.$ to $\left.2 \times 10^{-3} \mathrm{~Hz}\right)$ periodograms which were ensemble averaged. This highfrequency spectrum is nearly white, with variability increasing toward higher frequencies. The low-frequency spectrum was estimated using the near-bottom hourly speeds. In the $2 \times 10^{-6}$ to $2.3 \times 10^{-5} \mathrm{~Hz}$ band, 21 periodograms were obtained and averaged. The resulting spectrum shows a flat region from 6 to 1.8 days and a sharp drop at shorter periods. There are no tidal or inertial peaks in the spectrum.

The high-frequency spectrum is relevant to the choice of time interval used in forming averages. It is desirable to pick an averaging interval which is considerably larger than the time scale of motions in the logarithmic layer [Bowden, 1978]. We choose an averaging interval of $25.2 \mathrm{~min}$, corresponding to 6 times the sampling interval of $252 \mathrm{~s}$, as there is a local spectral minimum at the frequency $\left(6.6 \times 10^{-4}\right.$ $\mathrm{Hz}$ ) corresponding to this period (Figure 4). This averaging interval was used for all determinations of vector-averaged near-bottom speed, designated $\bar{U}$ in this work.

\subsection{Boundary Layer Scaling}

A rough boundary layer scaling, $z / L_{W}$, was attempted by computing, for each profile, an estimated boundary layer thickness based on the Weatherly and Martin [1978] formula

$$
L_{W}=1.3 \frac{u_{*}}{f}\left(1+\frac{N^{2}}{f^{2}}\right)^{-\frac{1}{4}}
$$

where $u_{*}$ is friction velocity, $f$ is the Coriolis parameter, and $N$ is Brunt-Väisälä frequency just above the boundary layer.

First, $u_{*}$ was calculated approximately as $\sqrt{C_{f}} \bar{U}$, with a drag coefficient $C_{f}=4.15 \times 10^{-3}$, using the $\bar{U}$ determination closest in time to the profile. Well-behaved profiles of current speed with logarithm of elevation close to the bed (during times when the influence of stratification was negligible) provided this estimate of $C_{f}$, together with an estimate of $z_{0}=3 \mathrm{~mm}$ for the roughness length. This value of $z_{0}$ implies a roughness element dimension of $d \approx 30 z_{0} \approx 0.1$ m [Wimbush and Munk, 1970], but sediment cores from the area show cohesive muds with grain sizes very much smaller than this [Flood, 1989]. Presumably, the flow is responding to a roughness determined by the furrows (or other bed forms). Indeed this value of $z_{0}$ is close to the value of $5 \mathrm{~mm}$ determined by Weatherly and Wimbush [1980] within a furrow on the Blake-Bahama Outer Ridge, where the bottom was of similar composition. Also the estimate of $C_{f}$ appears to be consistent with that of $z_{0}$, inasmuch as Sternberg [1968] found $C_{f}=4.0 \times 10^{-3}$ over rough gravel beds for which $d$ $=0.1 \mathrm{~m}$.

For each profile the approximate value of $u_{*}$ thus computed was used together with the temperature data close to the bed $T(z)$ to compute the Monin-Obukhov length scale

$$
L_{M}=\frac{u_{*}^{2}}{\kappa^{2} g a z \frac{d T}{d z}}
$$

where $g$ is gravity, $a$ is thermal expansion, and $\kappa=0.4$ is Von Kármán's constant. Then, from $\bar{U}$ an improved estimate of $u$ * was obtained using either

$$
\frac{\bar{U}}{u_{*}}=\frac{1}{\kappa}\left[\ln \left(\frac{z}{z_{0}}\right)+\frac{b z}{L_{M}}\right] \quad \frac{z}{\left|L_{M}\right|}<1
$$

or

$$
\frac{\bar{U}}{u_{*}}=\frac{1}{\kappa} \frac{b z}{L_{M}} \quad \frac{z}{L_{M}}>1
$$

where $z$ is the elevation at the bottom stop, and $b \approx 5[W e b b$, 1970]. 
Finally, for each profile, from $u_{*}$ computed in this way and from measured temperature data $T(z), L_{W}$ and $N$ were jointly estimated iteratively. Details of these calculations are given by Viekman [1988].

\subsection{Vertical Profiles of Convergence}

Data from each pair of simultaneous vertical profiles were compared to detect secondary circulations. Although the two Cyclesondes began their upprofiles or downprofiles at the same time, the measurement heights were variable because of differences in instrument vertical velocity and occasional bad data points. Interpolations of the data were therefore necessary to compare velocities at standard heights. Speed observations were first cubic-splineinterpolated [Press et al., 1985] to the heights of the heading data points (see section 2). Velocity was then resolved in geographical $u$ (eastward) and $v$ (northward) components, which were interpolated with cubic splines to standard heights. Details of the procedure are given by Viekman [1988]. To avoid spline overshoots, data points within a given profile which differed in height by $0.5 \mathrm{~m}$ or less were averaged. The splines were then sampled at standard heights above the bottom (5-m increment for $z>30 \mathrm{~m}, 1-\mathrm{m}$ increment for $2 \mathrm{~m}<z \leq 30 \mathrm{~m}$, and an additional sampling at $z=1.5 \mathrm{~m})$ and in boundary layer coordinates $\left(0.05-z / L_{W}\right.$ increment for $0.1 \leq z / L_{W} \leq 2.0$ ). In no cases were splines extrapolated lower than $0.8 \mathrm{~m}$ below the bottom stop, and

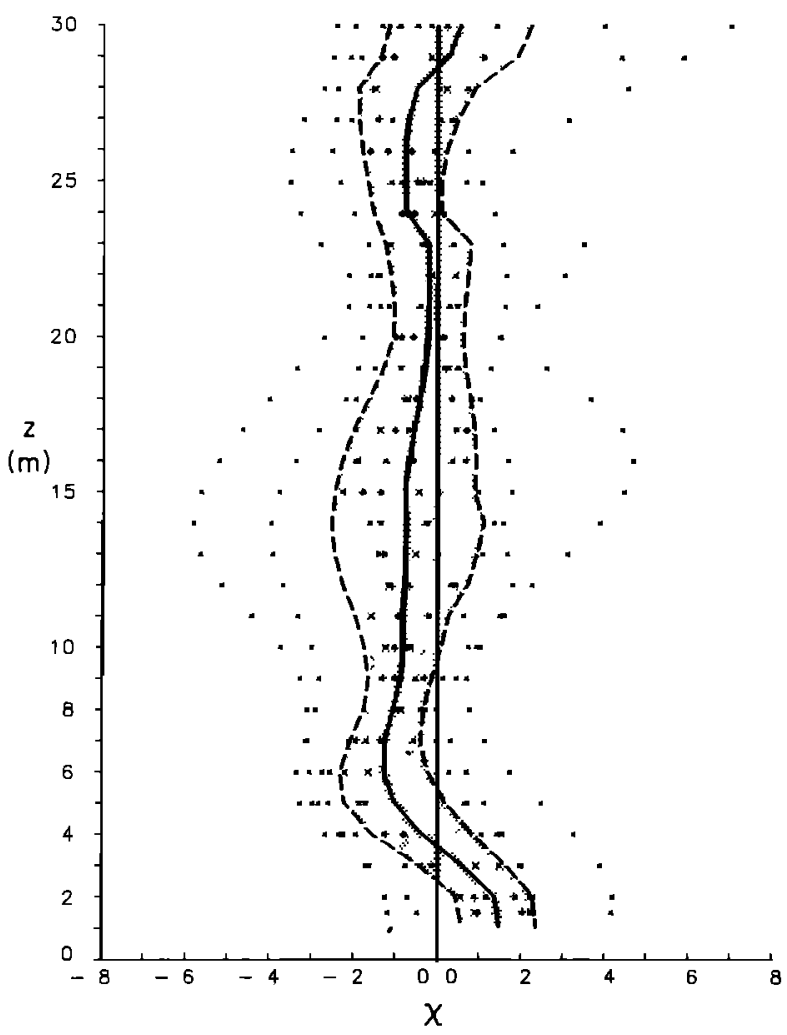

Fig. 5. Plot of relative convergence $\chi$ with height above bottom in meters, for 10 profiles for which $\bar{U} \geq 6 \mathrm{~cm} / \mathrm{s}$ and $\bar{\phi}<25^{\circ}$. The ensemble average is shown by a heavy solid line. The $90 \%$ confidence interval (computed from the $t$ distribution) is shown by the stippled area, and $\chi=0$ is shown by a light solid line.

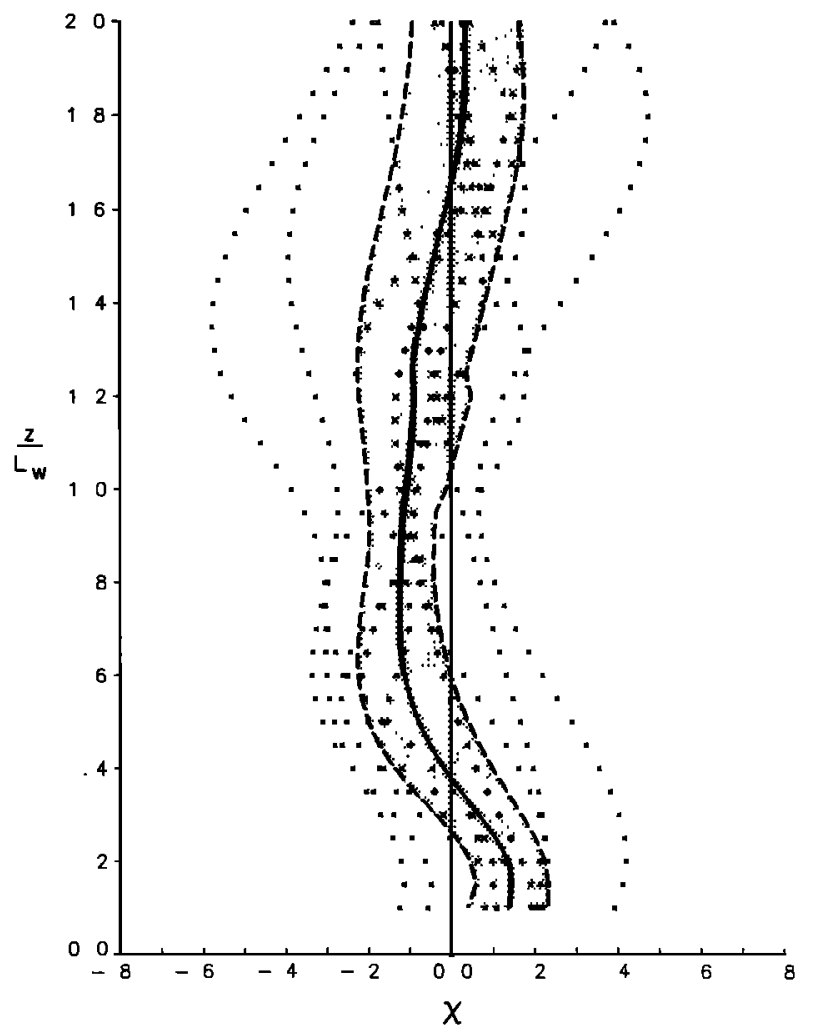

Fig. 6. Same as in Figure 5, but with height above bottom scaled by BBL thickness $L_{W}$.

points where interpolation extended beyond $5 \mathrm{~m}$ from the nearest data point were excluded from further analysis.

To quantify the secondary flow, relative convergence $\chi(z)$ was calculated. Convergence $\chi$ is here defined in a streamwise coordinate system ( $u$ parallel to the combined mean near-bottom flow for the two moorings) as crossstream velocity on the south mooring $\left(v_{s}\right)$ minus crossstream velocity on the north mooring $\left(v_{n}\right)$, normalized by the average of the two flow speeds at that level:

$$
\chi=\frac{\left(v_{s}-v_{n}\right)}{\frac{1}{2}\left[\left(u_{s}^{2}+v_{s}^{2}\right)^{\frac{1}{2}}+\left(u_{s}^{2}+v_{s}^{2}\right)^{\frac{1}{2}}\right]}
$$

Ekman veering, insofar as it is equal at the two moorings, subtracts out in this calculation, leaving only the secondary circulation. Additionally, arcsine of half the convergence thus calculated gives the angle of the total flow to the mean (primary) flow.

Figure 5 shows individual profiles and ensemble averages of $\chi(z)$ computed from the 10 Cyclesonde profile pairs for which vector-averaged, near-bottom flow has direction relative to the furrow $\bar{\phi}<25^{\circ}$ and speed $\bar{U}>6 \mathrm{~cm} / \mathrm{s}$. $L_{W}$ for these 10 profiles ranged from $7 \mathrm{~m}$ to $12 \mathrm{~m}$ with an average value of $10 \mathrm{~m}$. Figure 6 is the same as Figure 5 except that boundary layer scaling has been applied, so that individual profiles and ensemble averages of $\chi\left(z / L_{W}\right)$ are shown for the same 10 profile pairs. Ninety percent confidence intervals for the computed $\chi$ averages are also shown in both figures.

If Floods [1978, 1983] hypothesis is correct, we would expect to see mean flow toward the furrow near the bottom and away from the furrow at higher levels in the $\mathrm{BBL}$. Since 
TABLE 2. Relative Frequency of Double-Vortex Structures (Convergence Near the Bottom and Divergence Above) for Different Near-Bottom Speeds and Flow Orientations (Relative to Furrow Direction)

\begin{tabular}{ccccccccccc}
\hline \multirow{1}{*}{$\bar{\phi}$} & \multicolumn{8}{c}{ Near-Bottom Speed $\bar{U}, \mathrm{~cm} / \mathrm{s}$} \\
\cline { 2 - 10 } & $<3$ & $3-4$ & $4-5$ & $5-6$ & $6-7$ & $7-8$ & $9-10$ & $10-11$ & $12-13$ & $13-14$ \\
\hline$>45^{\circ}$ & $0 / 5$ & & $1 / 1$ & $1 / 3$ & & & & & $0 / 2$ & $0 / 1$ \\
$35^{\circ}-45^{\circ}$ & $0 / 3$ & $0 / 1$ & & $0 / 1$ & & & & & \\
$25^{\circ}-35^{\circ}$ & $0 / 2$ & & & $0 / 1$ & & & $0 / 2$ & & & \\
$15^{\circ}-25^{\circ}$ & $0 / 3$ & & $0 / 1$ & $0 / 1$ & $1 / 2$ & $1 / 1$ & & & \\
$5^{\circ}-15^{\circ}$ & $1 / 5$ & $0 / 3$ & $0 / 1$ & & $1 / 2$ & $1 / 1$ & & $0 / 1$ & & \\
$<5^{\circ}$ & $1 / 2$ & & & & & $2 / 2$ & $1 / 1$ & & & \\
\hline
\end{tabular}

Fractions $\mathbf{O} / \mathbf{P}$ indicate $O$ observed double-vortex structures in $\mathbf{P}$ total profiles in the bin.

the Cyclesondes were positioned on either side of a furrow, this means we would expect a change from positive $\chi$ near bottom to negative $\chi$ near $z=L_{W}$. This is not seen in every $\chi$ profile, though for all 10, $\chi$ does decrease between $z / L_{W}$ $=0.1$ (the lowest calculated level) and $z / L_{W}=0.5$ (Figure 6). But a spot-sampled flow parameter, such as instrument heading, is influenced by fluctuations caused by eddies or waves of any kind, and a single profile of $\chi$ (as computed here) may not be representative of convergence in the mean flow field. Averaging the data at each level reduces the effect of these fluctuations.

A sign change in average $\chi$, indicating a change from flow toward the furrow (i.e., $\chi>0$ ) to flow away from the furrow $(\chi<0)$, is seen in both natural and boundary layer coordinates. In Figure 5 (Figure 6) the ensemble averages show positive $\chi$ from the bed to an elevation of $z=3.8 \mathrm{~m}$ $\left(z / L_{W}=0.37\right)$ and negative $\chi$ for $3.8 \mathrm{~m}<z<29 \mathrm{~m}(0.37$ $\left.<z / L_{W}<1.65\right)$. In both coordinate systems, the average positive and negative values of $\chi$ are statistically distinct from zero at the $95 \%$ confidence level: statistically significant positive $\chi$ is observed up to $z=2.6 \mathrm{~m}\left(z / L_{W}=0.26\right)$, and statistically significant negative $\chi$ is observed for $5.5 \mathrm{~m}$ $<z<9.5 \mathrm{~m}\left(0.6<z / L_{W}<1.0\right)$. Other different reference levels $(z=5 \mathrm{~m}, 15 \mathrm{~m})$ for the streamwise coordinate system used in the calculation of $\chi$ were examined. Results based on these different reference levels were similar to those described above.

Table 2 shows the frequency of these observed structures at various flow speeds $\bar{U}$ and orientation magnitudes $\bar{\phi}$ of the flow relative to the furrow. The double-vortex pattern of bottom flow toward the furrow with mean flow away from the furrow at greater heights is seen in half of the profiles where speed is greater than $6 \mathrm{~cm} / \mathrm{s}$. For flows with $\bar{U}>$ $6 \mathrm{~cm} / \mathrm{s}$, frequency of double-vortex observations decreases as $\bar{\phi}$ increases. For $\bar{\phi}>25^{\circ}$, few double-vortex structures are seen.

Bottom mixed layers were absent in most profiles: for the 10 profiles pairs shown in Figures 5 and 6, median BruntVäisāla frequency (not shown) is typically $3.0 \times 10^{-3} \mathrm{~s}^{-1}$ at $z / L_{W}=0.2$, increasing to $5 \times 10^{-3} \mathrm{~s}^{-1}$ at $z / L_{W}=2.0$. Median Richardson number (Figure 7) is typically between 0.25 and 1 below $z / L_{W}=0.7$ and exceeds 1 at $z / L_{W}=0.7$ in the midst of the negative $\chi$ zone. These results show that the secondary circulations are not extinguished at the mod- erately large Richardson numbers (strong stratifications) observed at the experiment site.

One case in the record is indicative of the setup time for the vortices. At day 304, hour 2 , the current was in transition from westward flow to eastward flow. The appearance of the double-vortex structure is illustrated in Table 3 . In this case, the vortices had formed between hours 5 and 8 , coincident with the flow direction becoming roughly aligned with the furrow field (orientation $080^{\circ}$ ). Hence we can say that the setup time for the vortices is probably less than the 3-hour vertical sampling interval of the experiment. This rapid setup time suggests that rotational effects (i.e., Coriolis accelerations) are not of primary importance in setting up the secondary flow.

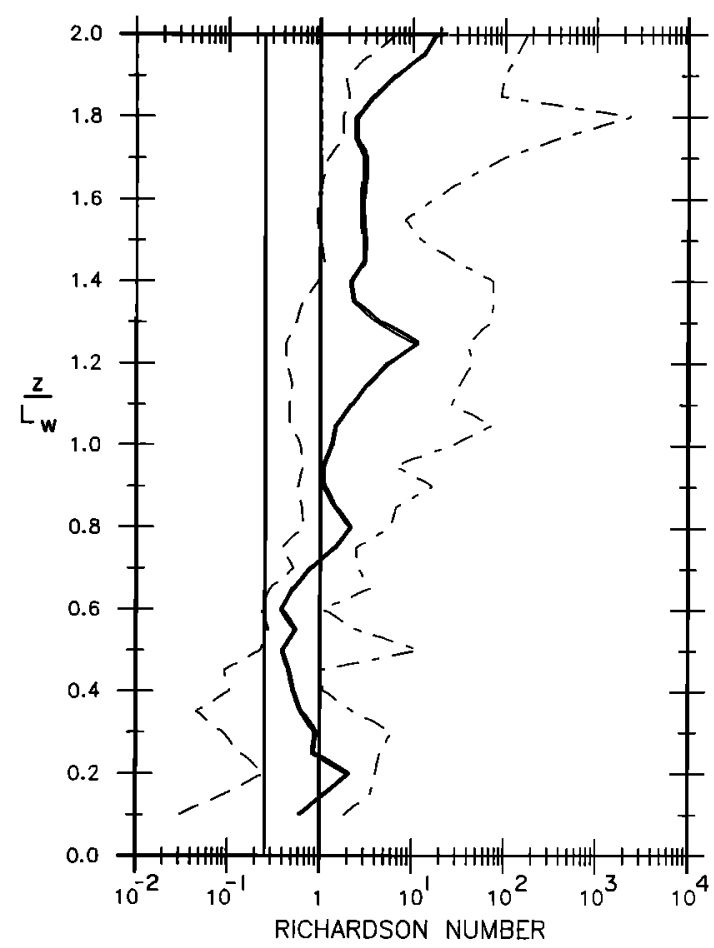

Fig. 7. Profile of median Richardson number for the 10 profiles in Figures 5 and 6. Upper and lower quartiles are shown by the dashed lines. Richardson numbers of $1 / 4$ and 1 are shown by light solid lines. 
TABLE 3. Double-Vortex Structure Formation During Directional Transition on Year Day 304

\begin{tabular}{|c|c|c|c|c|c|c|c|c|c|c|}
\hline \multirow{2}{*}{$\begin{array}{c}\text { Hour } \\
\text { EST }\end{array}$} & \multirow{2}{*}{$\begin{array}{c}\bar{U}, \\
\mathrm{~cm} / \mathrm{s}\end{array}$} & \multirow{2}{*}{$\begin{array}{c}u_{*}, \\
\mathrm{~cm} / \mathrm{s}\end{array}$} & \multirow{2}{*}{$\begin{array}{c}L_{W} \\
\mathbf{m}\end{array}$} & \multicolumn{3}{|c|}{ Maximum Divergence } & \multicolumn{3}{|c|}{ Maximum Convergence } & \multirow[t]{2}{*}{$\bar{\phi}$} \\
\hline & & & & $\overline{z, \mathrm{~m}}$ & $z / L_{W}$ & $x$ & $z, \mathrm{~m}$ & $z / L_{W}$ & $\chi$ & \\
\hline 2 & 6.0 & 0.31 & 5.7 & 4.3 & 0.75 & -0.61 & & none & & $31^{\circ}$ \\
\hline 5 & 9.5 & 0.61 & 10.3 & 13.9 & 1.35 & -0.58 & & none & & $56^{\circ}$ \\
\hline 8 & 9.4 & 0.47 & 9.3 & 7.9 & 0.85 & -0.09 & 1.9 & 0.20 & 0.23 & $86^{\circ}$ \\
\hline 11 & 7.3 & 0.39 & 7.0 & 5.2 & 0.75 & -0.30 & 1.0 & 0.15 & 0.10 & $80^{\circ}$ \\
\hline
\end{tabular}

\subsection{Errors}

Closed vortex circulations, as seen in the data, imply upward vertical velocity $w$ over the furrows. Cross-stream velocity $v$ should be comparable to this upward flow. The Cyclesonde data reduction process, however, assumes that upward velocity components are negligible. A non-zero vertical velocity introduces a potential source of error in the speed calculations, but would not significantly affect our principal results regarding relative flow convergence and divergence. Convergence depends mainly on differences in instrument heading, which is determined by the body of the Cyclesonde acting as a $\sim 2$-m-long vane. A vertical velocity component $(w)$ would, however, affect the rotor counts. Horizontal flow speed $(U)$ is obtained by solving the right triangle of instrument vertical velocity (determined from pressure differences) and total flow through the rotors (determined from rotor counts). For a current speed of $8 \mathrm{~cm} / \mathrm{s}$, and a typical instrument vertical travel speed of $10 \mathrm{~cm} / \mathrm{s}$ (Table 1 ), the flow sensed by the rotors would be $12.8 \mathrm{~cm} / \mathrm{s}$, if $w=0$. If a vertical flow component $w=0.05 \bar{U}$ were added, then the apparent horizontal flow speed determined from the Cyclesonde data would increase by $6 \%$ to $8.5 \mathrm{~cm} / \mathrm{s}$. But this $6 \%$ increase applies equally to both $u$ and $v$ components and so has little effect on convergence $\chi$.

Compass calibration errors would affect the $\chi$ results. Differences in absolute heading errors between the two instruments would cause a uniform offset of the calculated values of $\chi$, but the average $\chi$ values above $z=10 \mathrm{~m}$ (Figure 5) or $z / L_{W}=1$ (Figure 6) being statistically indistinguishable from zero suggests that these compasses are consistent with one another. Both instruments might have an equal offset (from true north), but in our calculations this would only affect $\bar{\phi}$ (vector-averaged near-bottom flow direction relative to the furrow). Compass calibrations are in fact reproducible to less than $1^{\circ}$, so we believe that measured $\bar{\phi}$ is accurate to better than $1^{\circ}$ and that convergence offset is consequently less than $2 \sin \left(1^{\circ}\right)=0.035$.

\subsection{Streamwise Vorticity}

We now turn to an estimate of the streamwise vorticity $\left(\Omega_{x}=\partial w / \partial y-\partial v / \partial z\right)$ associated with these secondary circulations. Considering the bottom-convergent doublevortex structure shown by the data, we would expect positive $\Omega_{x}$ at the right-hand mooring (looking downstream) and negative $\boldsymbol{\Omega}_{\boldsymbol{x}}$ at the left-hand mooring.

Values of $\partial v / \partial z$ may be obtained from the veering of the Cyclesonde, but we have no data on the $w$ velocity component. Values of $\partial w / \partial y$ may be roughly inferred from $\partial v / \partial z$ by an analysis of an idealized, elliptical, twodimensional streamline field $\left(\psi=f\left(y^{2} / a^{2}+z^{2} / b^{2}\right)\right.$, where $a$ and $b$ are half-lengths of major and minor axis, respectively), assuming that Ekman veering is the same at each mooring. Details are given by Viekman [1988]. We choose to evaluate vorticity of the secondary circulations $\left(\Omega_{x}^{\prime}\right)$ as the right-hand mooring vorticity minus the left-hand mooring vorticity divided by two, or

$$
\Omega_{x}^{\prime}=\frac{1}{2}\left[-\left(1+c^{2}\right) \frac{\partial v_{\text {Inst }}}{\partial z}\right]_{\text {right }}-\left[-\left(1+c^{2}\right) \frac{\partial v_{i n s t}}{\partial z}\right]_{\text {left }}
$$

where $c$ is the BBL thickness divided by half the furrow spacing.

Figure 8 shows a time series of these vorticity measurements, where the $z$ gradients are estimated from differences between measurements at the bottom stop and $z=5 \mathrm{~m}$. The vortex roll structures indicated by the mean $\chi$ profiles shown in Figures 5 and 6 are associated with positive $\Omega_{x}^{\prime}$. But while positive $\Omega_{x}^{\prime}$ implies negative $\partial \chi / \partial z$, it says nothing about the actual value of $\chi$ at any level: weak flow away from the furrow near the bottom may result in positive vorticity if $\chi$ is still more strongly negative further from the bed. Of the positive vorticity values, $37 \%$ (11 of 30 ) were associated with double-vortex observations, i.e., $\chi$ changing from positive near the bottom to negative higher up. The remainder typically showed a negative near-bottom $\chi$. For those profiles where $\bar{U}>6 \mathrm{~cm} / \mathrm{s}, 70 \%$ (7 of 10) of the positive vorticity values correlated with double-vortex observations. Average positive streamwise vorticity was $2.1 \times 10^{-3}$ $\mathrm{s}^{-1}$. All negative vorticities were associated with the absence of double-vortex structures (i.e., no $\chi$ sign change in the boundary layer). Similar analyses were conducted for the $1.5 \mathrm{~m} \leq z \leq 15 \mathrm{~m}$ range. Average positive streamwise vorticity there was only $5.1 \times 10^{-4} \mathrm{~s}^{-1}$.

Finally, vorticity values were also correlated with $u_{\text {. }}$ and $\bar{U}$. Of 19 profiles where $u_{*} \geq 0.3 \mathrm{~cm} / \mathrm{s}, 13 \mathrm{had}$ positive $\Omega_{x}^{\prime}$ values. Similarly, for $\bar{U} \geq 6 \mathrm{~cm} / \mathrm{s}, 10$ of 15 profiles had positive $\Omega_{x}^{\prime}$ values.

\section{Discussion}

We have found, for the first time, direct evidence of counterrotating, helical vortices in the bottom boundary layer over a region of sedimentary furrows. Our work confirms the streamwise vorticity structure associated with a furrow proposed by Flood [1978, 1983].

There are qualitative similarities between these bottom vortices and results from investigations into the structure of other turbulent boundary layers. We find cross-stream 


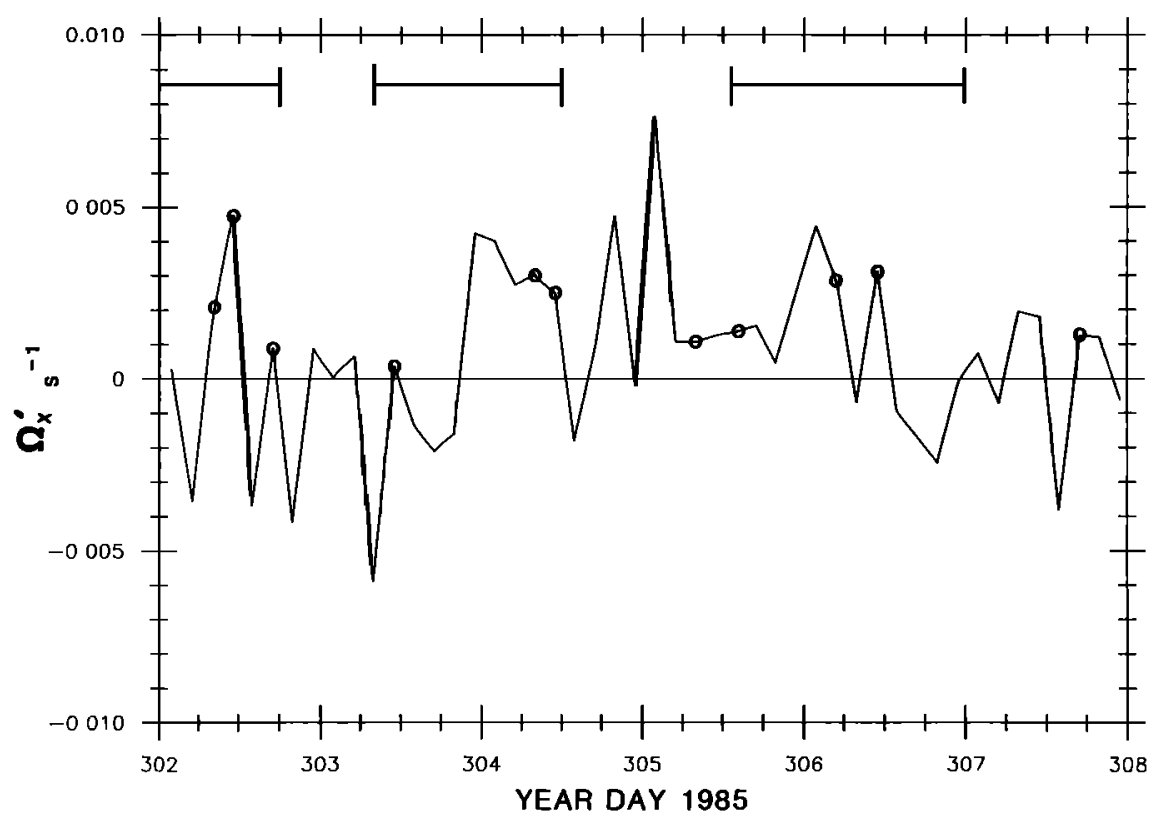

Fig. 8. Time series of streamwise vorticity $\Omega_{x}^{\prime}$ evaluated for the interval $1.5 \mathrm{~m} \leq z \leq 5.0 \mathrm{~m}$. Open circles indicate profile pairs where a sign change in $\chi$ was observed. Horizontal bars indicate high-speed, near-bottom flow periods. Positive $\Omega_{x}^{\prime}$ values generally correspond to paired-vortex flow, while negative values generally do not.

velocities of $3 \%$ to $10 \%$ of the free stream speed, comparing favorably with typical atmospheric values of $5 \%$ [Brown, 1970]. The angle of the total flow to the primary flow is about $5^{\circ}$. McLean [1981] does not give specific values from his flume experiments with transversely varying roughness, but a minimum angle of $1^{\circ}$ may be calculated from his description of the sweeping of neutrally buoyant beads.

We have found the strongest secondary circulation when the ratio of BBL thickness $L_{W}$ to furrow separation was about $1 / 6$. These results compare favorably with the results of Townsend [1976] and McLean [1981], who both found ratios of $1 / 4$. Their results were in neutrally stratified flows. Since stratification limits the upper extent of the boundary layer, the smaller ratio found here is not unexpected.

Flow speeds strongly associated with vortex presence in this study $(\bar{U}>6 \mathrm{~cm} / \mathrm{s})$ are similar to those from other furrowed locations. Flood [1983] shows flow speeds recorded over various furrow fields in the oceans, and most fall into the $5-$ to $15-\mathrm{cm} / \mathrm{s}$ range.

This experiment was designed to test the hypothesis that streamwise, counterrotating vortex structures are present in the turbulent boundary layer over a furrow field. The results confirm this hypothesis. Nevertheless, we could not draw strong inferences from the few profiles available for analysis. The coarse vertical sampling scheme dictated a reliance on interpolated values to interpret the flow patterns seen. Finer vertical sampling, more profiles during high flow speeds $(\bar{U}>5 \mathrm{~cm} / \mathrm{s})$, and a cross-stream array of more than two moorings would provide valuable information on the nature of these circulations.

Most of the reported furrows are found in the deep sea, where density stratification sometimes plays a role in controlling boundary layer thickness but generally has little influence on the friction velocity. The conditions at our study site were not typical in that strong thermal stratification provided limits to both boundary layer thickness and bottom stress, the thermal gradient being significant even close to the lake bed. In the atmospheric case, unstable stratification and the resulting convection play an important role in the development of the secondary circulation [Brown, 1970]. Nevertheless, it appears from our observations that these circulations can also form in flows with significant stable stratification.

We do not believe that the furrows are necessary for the formation of these streamwise vortices in the BBL, but furrows may strengthen the vortices and "lock" their positions by cross-stream changes in turbulent intensity. As previously discussed (section 1), streamwise counterrotating vortex circulation is a frequent form of instability leading to turbulence. Brown [1970] described the same phenomenon as "ubiquitous" in the atmosphere, citing numerous observations of parallel cloud lines. In the oceans, observations of streamwise lineations in the bottom are manifold (see, for example, Flood [1981, 1983], McLean [1981], and Allen [1969]), with furrows being an especially pronounced morphology. It may be that bottom vortex rolls in seas and lakes are as common as those in the atmosphere. Our results do demonstrate that longitudinal vortex flows are present in a furrowed area. We cannot distinguish cause and effect, but it seems plausible that the helical flow structure and the furrows may be mutually reinforcing.

We have found that the secondary circulations have their upper bound at $z / L_{W} \approx 1.0$ and that the boundary layer at the study site is significantly stratified $\left(N \approx 4 \times 10^{-3}\right.$ $\left.s^{-1}\right)$ even when the vortices are present. We have shown that the vortices form quickly in the presence of the furrows, and work reviewed earlier shows they can exist in nonfurrowed boundary layers as well. The profiles at year day 304, hour 11 , near the end of a 12-hour period of quasi-steady stratified flow, show a bottom mixed layer, which has thickened and 
become more thoroughly mixed as time progressed. Doublevortex flows are seen in half of the profiles during this steady period. This correspondence suggests these vortices may transport heat vertically in an initially stratified boundary layer, resulting in bottom mixed layers after further homogenization by smaller-scale turbulent fluctuations.

Acknowledgments. The National Undersea Research Program provided use of the Johnson Sea-Link submersible for the initial area survey and deployment of the moorings. We thank the officers and crew of the R/V Seward Johnson for their help in this work and also the officers and crew of the R/V Laurentian for their assistance in later work on the mooring systems. Mark Rowe and William Reynolds, from the Keweenaw region, provided valuable diving assistance. We had the benefit of fruitful discussions with Brad Butman, Georges Weatherly, Roger Flood, and Gieselher Güst and constructive comments from the anonymous reviewers. The U.S. Coast Guard provided B.E.V. the opportunity to attend graduate school through the Post-Graduate School program. This support is gratefully acknowledged. Our work was supported by the National Science Foundation under contracts OCE85-01432 and OCE85-01721.

\section{REFERENCES}

Allen, J. R. L., Erosional current marks of weakly cohesive mud beds, J. Sediment. Petrol., 39, 607-623, 1969.

Bowden, K. F., Physical problems of the bottom boundary layer, Geophys. Surv., 3, 255-296, 1978.

Brown, R. A., A secondary flow model for the planetary boundary layer, J. Atmos. Sci., 27, 742-757, 1970.

Cantwell, B. J., Organized motion in turbulent flow, Annu. Rev. Fluid Mech., 13, 457-515, 1981.

Elder, J. W., The flow past a flat plate of finite width, J. Fluid Mech., g, 133-153, 1960.

Flood, R. D., Studies of deep-sea sedimentary microtopography in the North Atlantic Ocean, Tech. Rep. WHOI-78-64, 395 pp., Mass. Inst. of Technol./Woods Hole Oceanogr. Inst. Joint Program in Oceanogr., Woods Hole, Mass., 1978.

Flood, R. D., Distribution, morphology, and origin of sedimentary furrows in cohesive sediments, Southampton Water, Sedimentology, 28, 511-529, 1981.

Flood, R. D., Classification of sedimentary furrows and a model for furrow initiation and evolution, Geol. Soc. Am. Bull., 94, 630-639, 1983.

Flood, R. D., Submersible studies of current-modified bottom topography in Lake Superior, J. Great Lakes Res., 15, 3-14, 1989.
Flood, R. D., and T. C. Johnson, Side-scan targets in Lake Superior-Evidence for bedforms and sediment transport, Sedimentology, 31, 311-333, 1984.

Leibovich, S., The form and dynamics of Langmuir circulations, Annu. Rev. Fluid Mech., 15, 391-427, 1983.

McLean, S. R., The role of non-uniform roughness in the formation of sand ribbons, Mar. Geol., 42, 49-74, 1981.

Press, W. H., B. P. Flannery, S. A. Teutolsky, and W. T. Vetterling, Numerical Recipes, 818 pp., Cambridge University Press, New York, 1985.

Sternberg, R. W., Friction factors in tidal channels with differing bed roughness, Mar. Geol., 6, 243-260, 1968.

Townsend, A. A., Entrainment and the structure of turbulent flow, J. Fluid Mech., 41, 13-46, 1970.

Townsend, A. A., The Structure of Turbulent Shear Flow, 429 pp., Cambridge University Press, New York, 1976.

Van Leer, J., W. Düing, R. Erath, E. Kennelly, and A. Speidel, The Cyclesonde: An unattended vertical profiler for scalar and vector quantities in the upper ocean, Deep Sea Res., 21, 385400, 1974.

Viekman, B. E., Secondary circulations in the bottom boundary layer over sedimentary furrows, M.S. thesis, 67 pp., Univ. of R.I., Kingston, 1988.

Weatherly, G. L., and P. J. Martin, On the structure and dynamics of the oceanic bottom boundary layer, J. Phys. Oceanogr., $8,557-570,1978$.

Weatherly, G. L., and M. Wimbush, Near-bottom speed and temperature observations on the Blake-Bahama Outer Ridge, $J$. Geophys. Res., 85, 3971-3981, 1980.

Webb, E. K., Profile relationships: The log-linear range, and extension to strong stability, Q. J. R. Meteorol. Soc., 96, 67-90, 1970.

Wimbush, M., and W. Munk, The benthic boundary layer, in The Sea, vol. 4(1), edited by A. E. Maxwell, pp. 731-758, WileyInterscience, New York, 1970.

B. E. Viekman, Marine Science Section, U.S. Coast Guard Academy, New London, CT 06320.

M. Wimbush, Graduate School of Oceanography, University of Rhode Island, Narragansett, RI 02882.

J. C. Van Leer, Rosenstiel School of Marine and Atmospheric Science, University of Miami, 4600 Rickenbacker Causeway, Miami, FL 33149.
(Received June 6, 1988; revised February 20, 1989; accepted August 4, 1988.) 